\title{
Research by senior registrars in psychiatry
}

\section{Lessons to be learned for the specialist registrar grade}

\author{
Christopher J. Williams and Stephen Curran
}

\begin{abstract}
All higher trainees in psychiatry are required to spend one day a week in research or further study. A crosssectional postal survey was used to investigate how senior registrars use their allocated research time, and to identify specific difficulties that prevent successful research being carried out. The instigation of the specialist registrar grade offers the chance to improve trainees' involvement in research. This has implications for the design and implementation of postgraduate teaching on research in psychiatry.
\end{abstract}

The postgraduate training of doctors aims to prepare the trainee for a post as consultant or senior lecturer. In the UK, higher training in psychiatry at senior registrar level has recently changed (from 1 July 1996) to a unified specialist registrar training post. It is therefore an opportune time to describe the research experience of the senior registrar grade so that lessons may be learned which are relevant for the training needs of the specialist registrar grade.

The Royal College of Psychiatrists requires all senior trainees in psychiatry to take part in research as part of their higher training (Joint Committee on Higher Psychiatric Training, 1995) and local training schemes are regularly assessed by the College to ensure that a balance of clinical and other training experience is available to trainees.

It is clear that trainees experience a range of difficulties in carrying out their research and several papers have examined why people choose to carry out research (Williams \& Curran, 1996). The aim of this study was to investigate the research experience of senior registrars in psychiatry in the Yorkshire and Northern regions and to identify whether the type (full-time or part-time) of training affects senior registrars' research experience.

\section{The study}

A standardised questionnaire was sent out in August 1995 to all senior registrars working within all specialities of psychiatry in the Northern and Yorkshire regions. The questionnaire could be completed anonymously and was made up of five sections:

(a) General information: including gender and whether they were full- or part-time.

(b) Active research: their motivation to do research and their current research activity.

(c) Practical problems with research: what problems have hindered research (e.g. time, lack of resources).

(d) Access to research resources: computer, word processor etc. and ability to use these.

(e) Supervision, training and support in research activity.

\section{Findings}

A total of 99 questionnaires were sent out and 57 (58\%) questionnaires were returned (56\% male, $44 \%$ female). Seventy-nine per cent of the responses were from full-time senior registrars. and $21 \%$ part-time.

\section{Active research}

Forty-eight (84\%) trainees were actively involved in some form of research, and only $9(16 \%)$ stated that they were doing no research. The research was registered for a university degree in nearly $30 \%$ of cases, and a similar number had registered their research with the local trust. Trainees pointed to a range of motivations for carrying out research (Table 1).

\section{Table 1. Motivation to do research $(n=57)$}

\begin{tabular}{lc}
\hline Reason & \\
\hline Own interest & $19(33 \%)$ \\
Curriculum vitae purposes & $17(30 \%)$ \\
Advance career & $13(23 \%)$ \\
To please others & $1(2 \%)$ \\
Missing data & $1(2 \%)$ \\
Other & $6(11 \%)$ \\
\hline
\end{tabular}


Problems with research

Problems carrying out research were common, with $61 \%$ of all respondents identifying difficulties associated with their research (Table 2).

\section{The effect of full-time/part-time employment on research}

There was widespread ignorance about the entitlement to research time. The majority $(86 \%)$ incorrectly stated that they were entitled to only one session of research time a week. The correct entitlement is two sessions, allowing eight sessions a month to do research (Joint Committee on Higher Psychiatric Training, 1995). In spite of this, $51 \%$ of full-time senior registrars $(n=45)$ spent six or less sessions per month carrying out research and less than half received their full allotted number of sessions. Similarly $64 \%$ of part-time senior registrars took two or less sessions a month, and only $33 \%$ took their full allocation of four sessions. There are no significant differences between the research activity of full- and part-time senior registrars, after the number of research sessions taken per month are compensated for.

Eighty-two per cent of part-time and $49 \%$ of full-time senior registrars experienced difficulties carrying out their research as a result of clinical work and this result was significant $\left(\chi^{2}=3.88\right.$, d.f. $\left.=1, P<0.05\right)$. Part-time trainees had significantly less access to a word processor (91\% of full-time and only $67 \%$ of part-time trainees, $\chi^{2}=4.69$, d.f. $=1, P<0.03$ ), and only $58 \%$ of part-time compared to $87 \%$ of full-time senior registrars believed they possessed the skills to carry out a CD-ROM review $\left(\chi^{2}=4.88\right.$, d.f. $=1$. $P<0.03)$. None of the part-time trainees believed they possessed the skills to use a statistical package compared with all $(100 \%)$ of full-time trainees.

\section{Access to research resources}

Although $46(81 \%)$ of trainees had access to a computer, between 67 and $84 \%$ did not have the skills necessary to use a computer, word

Table 2. Problems that have stopped or hindered research

\begin{tabular}{ll}
\hline Problem & \\
\hline Clinical work intrudes & $54 \%$ \\
Lack of time & $53 \%$ \\
Uncertainty how to proceed & $30 \%$ \\
Lack of support from senior staff & $30 \%$ \\
Lack of resources & $30 \%$ \\
Own lack of interest & $21 \%$ \\
Put off by the idea of writing a protocol & $12 \%$ \\
\hline
\end{tabular}

Research by senior registrars processor or carry out a CD-ROM literature review, and $65 \%$ stated that they could not use a statistical package. This may go some way to explaining why in over $20 \%$ of projects where data had been collected, the study remained uncompleted because of problems with data analysis or writing up.

\section{Quality of research supervision and training}

Access to adequate supervision and training is essential for effective research. Although $61 \%$ of senior registrars felt that they received adequate supervision and support from trainers, only $28 \%$ felt that this was 'good'. While $60 \%$ of trainees described their research training as 'good' or 'adequate', 39\% rated their training 'poor' or 'non-existent'. A majority $(63 \%)$ had received formal training in research, mostly within the setting of local university courses (39\%). Only 7\% had attended College training courses or workshops in research methodology.

\section{Comment}

The relatively low response rate (58\%) may have introduced bias into the sample. Respondents may over-represent those actively taking part in research or those experiencing difficulties with research. Even if the findings that almost $80 \%$ are keen to carry out research, and the majority are involved in research are interpreted with a degree of scepticism, our study shows that the main factor hindering research is a lack of available time. This problem is most acute for part-time senior registrars who as a group have more difficulties finding the time to carry out research and have less access to research training and less skills to use essential research resources.

It is clear from our findings that significant obstacles stand in the way of research by higher psychiatric trainees. With the recent changes to the specialist registrar grade, there needs to be greater understanding of how senior registrars use their research time and the difficulties associated with this. There is a need to develop a culture which fosters research. In the US, innovative schemes have successfully integrated active research with clinical work in the early postgraduate years (Anonymous, 1995) and such schemes could be piloted in the UK.

The development of a research activity logbook by the Joint Committee on Higher Psychiatric Training will focus the minds of both trainees and trainers alike on the need for adequate research training and experience. Surveys of trainees in surgical settings shows a clear correlation between the degree of satisfaction with research supervision and the subsequent impression of the value of the research (McCue, 1994). Specific and recurrent 
training in research methodology should be offered to trainees, and consultant and other trainers should aim to develop the necessary skills for effective research supervision. Hopefully, this will sew the seeds for longer-term interest and activity in research as trainees and later as trainers.

\section{Acknowledgements}

We thank the University of Leeds Max Hamilton Memorial Psychiatric Research Fund, Professor R. H. S. Mindham, Professor A. C. P. Sims and Miss Amanda Farrin (statistician) for their comments on an earlier draft of this paper.

\section{References}

ANONYMOUS (1995) Housestaff team research in the ambulatory setting: it can be done. Joumal of General Internal Medicine, 10, 219-222.
JOINT COMMITTEE ON HIGHER PSYChIATRIC TRAINING (1995) Joint Committee on Higher Psychiatric Training Handbook, 7th edn (Occasional Paper OP27). London: Royal College of Psychiatrists.

MCCUE, J. (1994) Research in surgical training: the trainees perspective. Annals of the Royal College of Surgeons of England, 76 (suppl. 3), 121-123.

WILLIAMS, C. J. \& CURRAN, S. (1996) Should psychiatric trainees do research? Psychiatric Bulletin. 20, 162164.

*Christopher J. Williams, Senior Lecturer, and Stephen Curran, Lecturer, Academic Unit of Psychiatry, Level 5, Clinical Sciences Building, St James's University Hospital, Beckett Street, Leeds LS9 7TF

*Correspondence

\section{Bereavement
Information Pack}

\section{For those bereaved through suicide or other sudden death}

\section{Kate Hill, Keith Hawton, Aslög Malmberg and Sue Simkin}

It is often difficult for relatives and friends of people who die by suicide or other sudden death to get help. This pack is specifically designed for such people. It highlights the areas of greatest difficulty for the bereaved person and offers advice on how to get support from friends and family and bereavement support and counselling organisations, as well as providing a list of recommended reading. A substantial number of bereaved individuals have already found it helpful. This pack is fully supported by The Samaritans and The Royal College of Psychiatrists.

$$
\text { - £5.00 } 1997 \bullet \text { ISBN } 1901242080
$$

Gaskell is the imprint of the Royal College of Psychiatrists. Gaskell books are available from good bookshops and from Book Sales, Publications Department, Royal College of Psychiatrists, 17 Belgrave Square, London SW1X 8PG (Tel. +44(0)171 235 2351, extension 146). The latest information on College publications is available on the INTERNET at: www.rcpsych.ac.uk 